\title{
BMJ Open Analysis of the burden and trend of injury in Sichuan, China, from 2006 to 2015: results from the national injury surveillance system
}

Peng Cai, ${ }^{1,2}$ Xianping Wu, ${ }^{3}$ Zhihao Liu, ${ }^{4}$ Ying Deng, ${ }^{3}$ Xiaofang Chen, ${ }^{5}$ Guanghui Yi, ${ }^{3}$ Jiang $\mathrm{Xu}^{2}{ }^{2}$ Shirong Huang, ${ }^{2}$ Rongsheng Luan ${ }^{1}$

To cite: Cai P, Wu X, Liu Z, et al. Analysis of the burden and trend of injury in Sichuan, China, from 2006 to 2015: results from the national injury surveillance system. BMJ Open 2019;9:e031184. doi:10.1136/ bmjopen-2019-031184

- Prepublication history and additional material for this paper are available online. To view these files, please visit the journal online (http://dx.doi. org/10.1136/bmjopen-2019031184).

$\mathrm{PC}$ and XW contributed equally.

Received 06 May 2019 Revised 16 October 2019 Accepted 23 October 2019
Check for updates

(C) Author(s) (or their employer(s)) 2019. Re-use permitted under CC BY-NC. No commercial re-use. See rights and permissions. Published by BMJ.

For numbered affiliations see end of article.

Correspondence to Dr Rongsheng Luan; Luan_chuan123@163.com

\section{ABSTRACT}

Objective This study investigates the distribution, burden and trends of injuries in Sichuan, China.

Design A surveillance study using injury data collected by the National Injury Surveillance System.

Setting and participants 312511 injury cases reported in the National Injury Surveillance System in Sichuan, China, from 2006 to 2015.

Primary outcome measures Years of potential life lost (YPLL) were calculated to determine the disease burden from injuries. Trend analysis was performed to assess the trends in specific injuries over time.

Results A total of 312511 injury cases were reported in the last 10 years in Sichuan with 192904 (men: 58.58\%) and 119607 (men: 67.11\%) cases from the urban and rural surveillance hospitals, respectively. The annual number of injury cases increased from 21257 in 2006 to 44112 in 2015 with an average annual increase of $8.45 \%$. The top three common causes of injury were fall (29.3\%), animal-related injury (19.1\%) and road-related injury $(14.6 \%)$ in the urban area and fall $(38.4 \%)$, road-related injury (17.2\%) and blunt injuries (16.0\%) in the rural area. YPLLs from injuries accounted for $13 \%$ of the total YPLLs in the urban area.

Conclusions The number of injury cases varied according to rural/urban areas and gender and increased sharply in Sichuan over the last decade. It is necessary to develop targeted prevention and control measures to reduce the disease burden of injuries.

\section{INTRODUCTION}

The WHO estimates that injuries cause over 58 million deaths each year that accounts for $10 \%$ of all global deaths. Injuries are the leading cause of death in the population aged 5 to 44 years. ${ }^{1}$ According to the Global Burden of Diseases (GBD) 2010 report, injury-related disability-adjusted life years (DALYs) account for $12.4 \%$ of all-cause DALYs globally. ${ }^{2-4}$ In China, 200 million injury events occur each year that leads to 14 million hospitalisations and one million disabilities. Injuries affect the health and welfare of all age groups because of disability, medical costs and premature

\section{Strengths and limitations of this study}

- This study examined the distribution, burden and trend of injuries in the Sichuan over a 10 year period based on a surveillance system with strict quality control.

- One limitation is that this study uses data from a facility-based surveillance system, and populationbased incidence rates cannot be generated easily based on this data.

- Moreover, deaths that occurred outside hospitals were not captured in the current study, and injuryrelated deaths were underestimated.

death. ${ }^{5-8}$ Estimating injury-related incidence and mortality is essential for raising awareness of injury burden and proposing effective policies and strategies to reduce this public problem.

Injury surveillance systems are essential to identify at-risk populations, support prevention efforts and evaluate the effects of prevention strategies. ${ }^{9}$ The WHO recommended that countries and regions should establish and maintain injury surveillance systems to systematically collect injury data based on their available resources. ${ }^{10}$ The WHO published injury surveillance guidelines that aim to guide healthcare professionals with practical assistance to develop and maintain injury surveillance systems. ${ }^{10}$ Many developed countries, including the USA and Canada, have set-up national surveillance systems for injuries. ${ }^{11} 12$ The lack of high-quality data on injuries to inform decision-making leads to less advanced injury prevention efforts in low- and middle-income countries, including China, than in developed countries. ${ }^{9} 1314$

The National Injury Surveillance System (NISS), the first hospital-based national system in China, was established in 2006 to understand the burden of injuries. ${ }^{15}$ Sichuan 
Province, located in southwestern China, has a population of 83.41 million and covers an area of $486000 \mathrm{~km}^{2}$. Injuries are the fourth leading cause of death both in Sichuan and in China. Results from the study in Sichuan will serve to inform the development of local injury prevention strategies and facilitate targeted injury prevention policies. The objectives of this study were to track the burden and trend of injuries in Sichuan using data from the NISS collected between 2006 and 2015 .

\section{METHODS}

\section{Surveillance hospitals}

The surveillance hospitals were from the NISS in Sichuan. ${ }^{15}$ The NISS was established in China in 2006, and 126 hospitals from 43 sample locations, including 23 rural and 20 urban sites, were recruited. ${ }^{15}$ There were two sample locations in Sichuan: the Qingyang District in Chengdu (urban) and Miyi County in Panzhihua (rural). In the Qingyang, the largest tertiary hospital and two secondary hospitals were selected as urban surveillance hospitals. In Miyi County, the hospital with the largest number of outpatients in the local area and two general township health centres were selected as rural surveillance hospitals.

\section{Case recruitment}

In the surveillance hospitals, an injury case was defined as the first hospital visit or presentation due to an injury event to an emergency room, outpatient department or other clinical departments. Cases were excluded if they were transferred from other medical institutions or were repeat visits to the same hospital for the same injury event. An injury was defined as damage to the physical body by acute exposure to energy or due to a lack of a vital element with the International Classification of Diseases (ICD) codes of S00 to T98.

\section{Data collection}

The National Injury Surveillance Form was used to collect information for all eligible injury cases between $1^{\text {st }}$ January, 2006, and $31^{\text {st }}$ December, 2015. This included patient demographics, basic information regarding the injury event and clinical information associated with the event (table 1). Trained doctors and nurses recorded injury and medical information of the patients using the NISS surveillance form. Subsequently, the forms were collected and archived by the prevention and health protection department of each hospital and reported to the local county or district Centres for Disease Control and Prevention (CDC) every month. In the county or district CDC office, the data were entered into a database using a uniform and specialised software (National Injury Information System). The electronic data were reported to the provincial CDC each quarter. ${ }^{15}$

External causes of injury were classified based on the International Classification of External Causes of Injury. ${ }^{16}$ The severity of the injuries were classified into
Table 1 Data elements of national injury surveillance form

\begin{tabular}{ll}
\hline Category & Example elements \\
\hline Demographics & $\begin{array}{l}\text { Age, sex, occupation, ID, education } \\
\text { level and occupation }\end{array}$ \\
$\begin{array}{l}\text { Basic information } \\
\text { of the injury event }\end{array}$ & $\begin{array}{l}\text { Time of injury occurrence, time of } \\
\text { treatment, mechanism, place and } \\
\text { activity of injury occurrence and intent } \\
\text { of injury }\end{array}$ \\
$\begin{array}{l}\text { Clinical } \\
\text { information of the } \\
\text { injury event }\end{array}$ & $\begin{array}{l}\text { Nature of injury, body part injured, } \\
\text { severity, clinical diagnosis and } \\
\text { disposition of injury }\end{array}$ \\
Other information & $\begin{array}{l}\text { Name of data reporter and date of } \\
\text { reporting }\end{array}$ \\
\hline
\end{tabular}

three categories with the following definitions: (1) Minor injury: no apparent or just slight or superficial injury, for example, bruises and minor cuts; (2) Moderate injury: required sutures or skilled treatment, for example, fractures; (3) Severe injury: required intensive medical or surgical management, for example, internal haemorrhage, punctured organs and severed blood vessels.

\section{Quality control}

The data accuracy and completeness of our study were ensured with the following strategies. First, face-to-face training sessions were held with item-by-item explanations of all data elements at all provincial and local CDCs and surveillance hospitals. All trainees received a working manual of the project with details regarding data entry. All trainees were tested, and those who failed were retrained. Additionally, after the establishment of the NISS, quality control efforts focusing on data collection, processing, entering and reporting at different levels were established. ${ }^{15}$

\section{Statistical analyses}

Categorical variables were reported as numbers and proportions. $\mathrm{X}^{2}$ tests were used to calculate the significance of the differences between groups. Years of potential life lost (YPLL) were calculated to evaluate the disease burden from injuries. A two-sided $\mathrm{p}$ value $<0.05$ was considered statistically significant. All statistical analysis was performed with SAS 9.2 and JMP 10.0 software (SAS Institute Inc, Cary, North Carolina, USA).

\section{Patient and public involvement}

Patients and the public were not involved in the design and conception of this study.

\section{RESULTS}

\section{Injury case demographics}

A total of 312511 injury cases were reported over the last 10 years from 2006 to 2015 in Sichuan with 192904 (men: $58.58 \%$ ) and 119607 (men: 67.11\%) from urban and rural surveillance hospitals, respectively (table 2 ). There were more men than women in both the urban and 


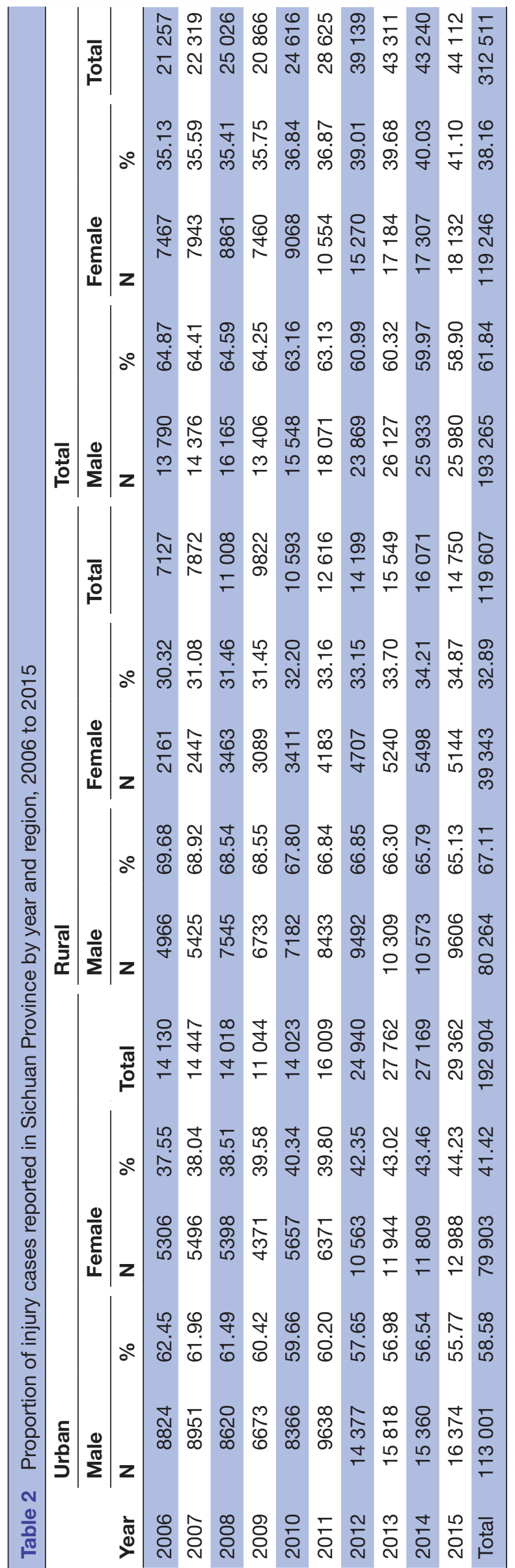

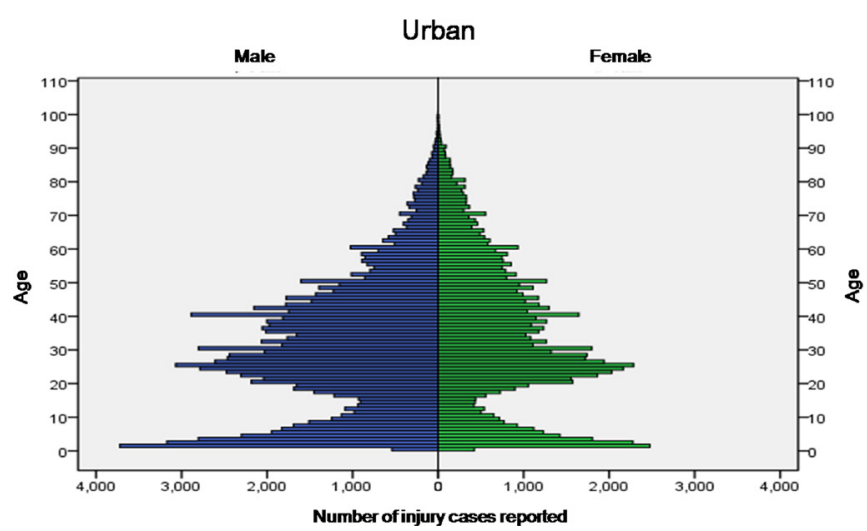

Figure 1 Age-specific and gender-specific proportions of injury from the urban area.

rural areas. The proportion of men was higher in rural than in urban surveillance hospitals $(67.11 \%$ vs $58.58 \%$, $\mathrm{p}<0.001)$. Age-specific and gender-specific proportions of injury from the urban and rural areas are presented in figures 1 and 2, respectively. There were peaks in the injury rates at 0 to 4 and 20 to 29 years of age in urban residents and at 35 to 44 years of age in rural residents (table 3).

\section{Trends in injury cases from 2006 to 2015}

The annual number of injury cases reported increased from 21257 in 2006 to 44112 in 2015 with an annualised rate of increase of $8.45 \%$. The annualised rate of increase was $8.47 \%$ and $8.42 \%$ in the urban and rural areas, respectively. From 2006 to 2015, the proportion of women increased from $35.13 \%$ to $41.10 \%$. This trend was observed in both the rural and urban areas.

\section{Mechanisms of injury}

The three leading causes of injury in the urban area were fall $(29.3 \%)$, animal-related injury $(19.07 \%)$ and roadrelated injury $(14.56 \%)$ and in the rural area were fall $(38.38 \%)$, road-related injury $(17.17 \%)$ and injury by blunt object $(16.03 \%$ ) (table 4$)$. The causes of injury were different in rural and urban areas. Fall was the primary cause of injury in both the urban and rural areas, especially in children and older people. Falls accounted for

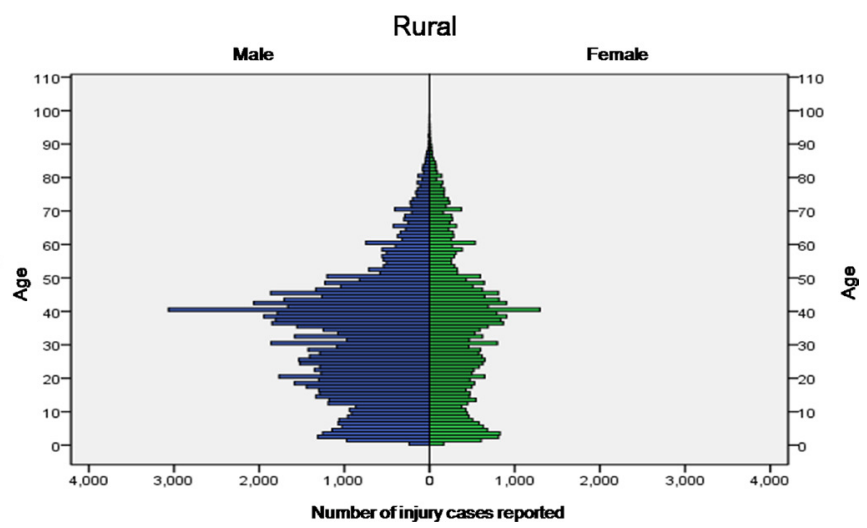

Figure 2 Age-specific and gender-specific proportions of injury from the rural area. 

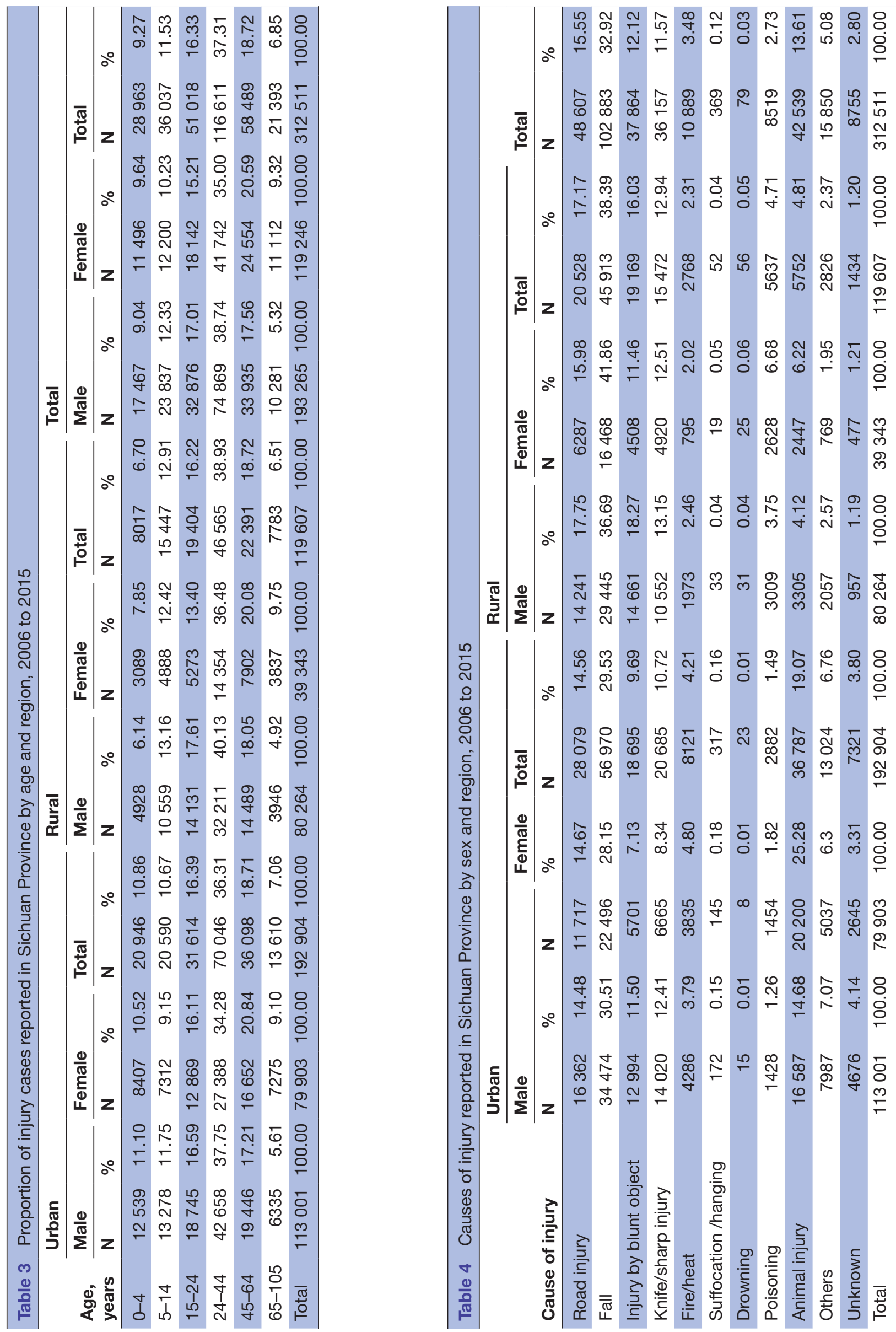
$53.7 \%, 47.5 \%, 25.1 \%, 24.8 \%, 30.7 \%$ and $48.9 \%$ of the total injuries in people aged 0 to 4,5 to 14,14 to 24,25 to 44,45 to 64 and over 65 years, respectively. The severity of injuries was different according to regions and gender. The proportion of moderate-to-severe injuries was higher in the rural area than in the urban area $(26.15 \%$ vs $20.58 \%, \mathrm{p}<0.001)$ and was higher in men than in women (24.53\% vs $19.76 \%, \mathrm{p}<0.001)$. The proportion of severe injuries was higher in urban areas than in rural areas $(4.67 \%$ vs $1.71 \%)$, as shown in online supplementary table 1 . Motor vehicle injuries were the leading cause of severe injuries $(24.90 \%)$ followed by falls $(24.26 \%)$; For moderate injuries, falls were the leading cause $(33.32 \%)$ followed by other injuries (data shown in online supplementary figures 1,2 ).

\section{Disease burden from injuries}

In the Qingyang District, Chengdu, the disease burden analysis in urban surveillance hospitals was calculated using YPLL up to 70 years based on the Chinese National Disease Surveillance Points data from 2010 to 2014. In total, the estimated YPLL was 83 063. Injuries accounted for 12.7\% (10 578) of the total YPLL from 2010 to 2014. Injury-related, age-standardised YPLL in the standard Chinese population in 2010 accounted for $13.1 \%$ of the total age-standardised YPLL.

Working Years of Potential Life Lost (WYPLL) were calculated based on the Chinese National Disease Surveillance Points data from 2010 to 2014 using the upper age limit of 60 (the retirement age in China). In total, the estimated WYPLL was 40 701. Injuries accounted for 16.7\% (6791 WYPLL) of the total WYPLL from 2010 to 2014. The injury-related, age-standardised WYPLL in the standard Chinese population in 2010 accounted for $17.5 \%$ of the total age-standardised WYPLL. Injuries accounted for a higher proportion of WYPLL than YPLL (17.5\% vs $13.1 \%, \mathrm{p}<0.01)$, implying that injury-related deaths occurred more in the labour force than the rest of the population and thus, were an economic burden.

\section{DISCUSSION}

\section{Main findings}

In this study, we examined the distribution, burden and trend of injuries in Sichuan using data from the NISS during a 10 year period (2006 to 2015). Additionally, we conducted detailed subanalyses by gender, age and urban/rural residence. Our results indicated that injuries are an increasingly alarming public health problem in China over the last 10 years. Moreover, our study highlighted the high-risk population groups prone to injury which is useful for guiding prevention strategies and developing important public health initiatives.

\section{Previous information in the literature}

Decreasing the injury burden is a major public health challenge for China in the upcoming decades. ${ }^{17} 18$ The first step to address the injury burden is to understand the magnitude and the distribution of causes. ${ }^{19}$ Before the establishment of the NISS in Sichuan, the regional injury burden data were collected mainly by the National Disease Surveillance Points System which provided only a partial description of the true size of the injury problem. ${ }^{14}$ A comprehensive surveillance system for injuries was desperately needed to guide the control of injury burden. ${ }^{20}$ In 2006, the establishment of an injury surveillance system in Sichuan supported the development of an epidemiological study on injuries, injury prevention and control measures. It is an irreplaceable part of the disease monitoring system in this province as it monitors injuries and death and is the most reliable source of injury data. ${ }^{15}$

\section{What this study adds}

In the last decade, the annual number of reported injuries in Sichuan increased from 21257 in 2006 to 44112 in 2015, with an average annual rate of increase of $8.45 \%$. This is in line with reported studies from the NISS and death registration data. ${ }^{152}$ Haagsma's study from GBD reported a decline in unintentional injury from 1990 to 2013, including in China, ${ }^{3}$ but the current study found that the annual number of reported injuries increased from 2006 to 2015 in Sichuan. The difference between the two studies may be explained partly by the disparity in study design between the two studies. In our study, only injured patients visiting hospitals were captured, and deaths that occurred outside hospitals were not reported. However, in Haagsma's study from GBD, they collected death information from vital registration cases as well as cases with injuries that did not receive care. ${ }^{3}$

Injuries are the fourth leading cause of death for residents in Sichuan and account for $13.1 \%$ of the total age-standardised YPLL. It is associated with a 0.5 year reduction in life expectancy and ranks second after noncommunicable diseases in regional disease burden aetiologies. Therefore, undertaking injury prevention and control projects can be economically convenient and effective to reduce the burden of disease in the region and improve life expectancy.

According to Zhou's study, the annual potentially productive years of life lost from injury were 12.6 million years, more than that from any disease group in China. ${ }^{22}$ Moreover, the annual economic costs of injury are almost four times the total government public health expenditure. In our study, the average annual increase in injury of $8.45 \%$ is a huge threat to economic development. In recent years, because of an increase in migration to urban areas for work, the population in rural years has severely decreased. An increase in injury-related YPLL will further lead to a loss in the labour force in rural areas which increases the burden on the agricultural economy and national vitals. Moreover, there is a disparity in access to medical care between urban and rural areas. Urban populations account for only $30 \%$ of the total population but use $80 \%$ of total health resources. ${ }^{23}$ The difference in medical welfare may cause more labour loss and deaths in rural areas than in urban areas. 
The occurrence of injuries is not simply accidental and can be prevented and avoided. Injury prevention and control can be accomplished by social system engineering based on the epidemiological characteristics of the injuries such as the causes and distribution of injuries between genders, age and location. Since the patterns of different causes of injury are diverse, the injury prevention strategies should be developed accordingly. For instance, fall prevention should be emphasised in children and older people, and traffic safety initiatives should target adults. High animal bites in urban areas suggest these are from domestic animals, and therefore, presentations at emergency rooms are likely to reduce the threat to life and fear of rabies. This study collected information from outpatient and emergency departments and set-up the first comprehensive surveillance system in Sichuan. Based on NISS, our study clarified the epidemiological characteristics of and factors influencing injury events such as the burden of injuries in urban and rural areas of Sichuan. These results provide local governments with valuable scientific information that can be used to develop prevention and control policies and strategies. ${ }^{182}$

\section{Limitations of the study}

This study has several limitations. First, NISS is a facilitybased, surveillance system and population-based incidence rates cannot be easily generated, similar to other surveillance systems. ${ }^{18}$ Second, specialist hospitals were not included in the sample, for example, children's and military hospitals, and thus, the data could be skewed. Third, only the alive, injured population visiting hospitals was captured, and deaths that occurred outside hospitals were not reported. Thus, injury-related deaths may be underestimated in our study.

\section{CONCLUSIONS}

Injury control and prevention should be of high priority among public health initiatives in Sichuan. Our study has provided important information to help develop policies and programme that can deliver effective measures and disseminate information for injury prevention in highrisk populations and to the entire populace to decrease the burden of injuries.

\section{Author affiliations}

${ }^{1}$ Department of Epidemiology, Sichuan University West China School of Public Health, Chengdu, China

${ }^{2}$ Department of Non-communicable Disease Control and Prevention, Center for Disease Control and Prevention of Qingyang District, Chengdu, China

${ }^{3}$ Institute of Non-communicable Disease Control and Prevention, Sichuan Center for Disease Control and Prevention, Chengdu, China

${ }^{4}$ Institute for Health Education, Jiangsu Provincial Center for Disease Prevention and Control, Nanjing, China

${ }^{5}$ Department of Epidemiology and Health Statistics, Public Health School, Chengde Medical College, Chengde, China

Acknowledgements We would like to thank the Chronic Disease Center of the Chinese Center for Disease Control and Prevention and the National Injury Monitoring System for their support of this study. We would like to thank Editage ( www.editage.com) for English language editing and Jia Liu from Center for Disease Control and Prevention of Qingyang District, Chengdu, for collecting the data.

Contributors PC, XW and RL conceived the study idea. PC and XW conducted the data analyses. $P C$ and $Z L$ conducted the literature review and drafted the manuscript. PC, XW, ZL, YD, XC, GY, JX, SH and RL contributed to refining the analytical framework and data interpretation. This final manuscript was read and approved by all authors.

Funding This research was supported by the Research Project of Sichuan Provincial Health Bureau (grant number 070120) and Special Survey Program for Scientific and Technological Basic Resources of the Ministry of Science and Technology (grant number 2017FY101205).

Competing interests None declared.

Patient consent for publication Not required.

Ethics approval The study was approved by the Ethical Review Committee of the National Center for Chronic and Non-communicable Disease Control and Prevention, Chinese Center for Disease Control and Prevention, Beijing, People's Republic of China.

Provenance and peer review Not commissioned; externally peer reviewed.

Data availability statement Data may be obtained from a third party and are not publicly available.

Open access This is an open access article distributed in accordance with the Creative Commons Attribution Non Commercial (CC BY-NC 4.0) license, which permits others to distribute, remix, adapt, build upon this work non-commercially, and license their derivative works on different terms, provided the original work is properly cited, appropriate credit is given, any changes made indicated, and the use is non-commercial. See: http://creativecommons.org/licenses/by-nc/4.0/.

\section{REFERENCES}

1 World Health Organization. Violence, injuries and disability biennial report, 2006-2007. Geneva: World Health Organization, 2008.

2 Global Burden of Disease Study 2013 Collaborators. Global, regional, and national incidence, prevalence, and years lived with disability for 301 acute and chronic diseases and injuries in 188 countries, 19902013: a systematic analysis for the global burden of disease study 2013. Lancet 2015;386:743-800.

3 Haagsma JA, Graetz N, Bolliger I, et al. The global burden of injury: incidence, mortality, disability-adjusted life years and time trends from the global burden of disease study 2013. Inj Prev 2016;22:3-18.

4 GBD 2013 Mortality and Causes of Death Collaborators. Global, regional, and national age-sex specific all-cause and causespecific mortality for 240 causes of death, 1990-2013: a systematic analysis for the global burden of disease study 2013. Lancet 2015;385:117-71.

5 Fang X, Zeng G, Linnan HW, et al. The incidence and economic burden of injuries in Jiangxi, China. Public Health 2016;138:138-45.

6 Jiang G, Choi BCK, Wang D, et al. Leading causes of death from injury and poisoning by age, sex and urban/rural areas in Tianjin, China 1999-2006. Injury 2011;42:501-6.

7 Yin Z, Wu J, Luo J, et al. Burden and trend analysis of injury mortality in China among children aged 0-14 years from 2004 to 2011. BMJ Open 2015;5:e007307.

8 Liu Q, Zhang L, Li J, et al. The gap in injury mortality rates between urban and rural residents of Hubei Province, China. BMC Public Health 2012;12:180.

9 Krug EG. Injury surveillance is key to preventing injuries. Lancet 2004;364:1563-6.

10 Holder YPM, Krug E, Lund J, et al, eds. Injury surveillance guidelines. Geneva: World Health Organization, 2001.

11 Quinlan KP, Thompson MP, Annest JL, et al. Expanding the National electronic injury surveillance system to monitor all nonfatal injuries treated in US hospital emergency departments. Ann Emerg Med 1999;34:637-45.

12 Mackenzie SG, Pless IB. CHIRPP: Canada's principal injury surveillance program. Canadian hospitals injury reporting and prevention program. Inj Prev 1999;5:208-13.

13 Wang SY, Li YH, Chi GB, et al. Injury-Related fatalities in China: an under-recognised public-health problem. Lancet 2008;372:1765-73.

14 Ma S, Li Q, Zhou M, et al. Road traffic injury in China: a review of national data sources. Traffic Inj Prev 2012;13(Suppl 1):57-63.

15 Duan L, Deng X, Wang Y, et al. The National injury surveillance system in China: a six-year review. Injury 2015;46:572-9. 
16 WHO Working Group on Injury Surveillance Methods. International classification of external causes of injuries (ICECI): data dictionary, version 1.1a. Adelaide: Consumer Safety Institute, Amsterdam and AlHW National Injury Surveillance Unit, 2003.

17 Ning P, Cheng X, Zhang L, et al. [Injury mortality in China, from 1990 to 2010]. Zhonghua Liu Xing Bing Xue Za Zhi 2015;36:1387-90.

18 Zhang L, Li Z, Li X, et al. Study on the trend and disease burden of injury deaths in Chinese population, 2004-2010. PLoS One 2014;9:e85319.

19 Krug EG, Sharma GK, Lozano R. The global burden of injuries. Am J Public Health 2000;90:523-6.
20 Hu G, Baker TD, Li G, et al. Injury control: an opportunity for China. Inj Prev 2008;14:129-30.

$21 \mathrm{Hu}$ G, Baker T, Baker SP. Comparing road traffic mortality rates from police-reported data and death registration data in China. Bull World Health Organ 2011;89:41-5.

22 Zhao Z, Svanström L. Injury status and perspectives on developing community safety promotion in China. Health Promot Int 2003;18:247-53.

23 Zhou Y, Baker TD, Rao K, et al. Productivity losses from injury in China. Inj Prev 2003;9:124-7. 